\title{
Reactive Power Cost Optimization Acquiring the Combined Properties of Static and Aggregate Dynamic Load as Composite Load Model
}

\author{
Nitin Kumar Saxena, Ashwani Kumar, Gebrehiwot Gebreyohans
}

\begin{abstract}
In electrical systems especially isolated wind and diesel based hybrid systems, voltage control has been achieved in several works from adequate supply of reactive power using STATCOM/SVC as dynamic compensators. However, in most of the existing works, studies are performed only with static loads which do not have any influence of previous system conditions. In such available studies, the two major concerns were (i) cost based studies, and (ii) control techniques of dynamic compensation. The electrical systems are always influenced by the unrealistic load modelling in such systems which is almost untouched in available works and therefore motivate the authors to work on it. Realistic loads are of composite nature that composes the blend of characteristics that acquire static as well as dynamic nature of the load. In present work, the authors are interested to investigate the lower cost of reactive power with composite load for best proportion of dynamic and static compensations. The study is done in MATLAB software with $10 \%$ step increment in reactive power demand and input wind power to analyse compensation effect for extreme voltage deviation of $\pm 0.1 \mathrm{pu}$ at load end as recommended by several energy policies and standard IEC 60038.
\end{abstract}

Keywords: Static and dynamic compensators, reactive power compensation cost, composite load model, aggregate dynamic load, and cost optimization

\section{NOMENCLATURE}

\begin{tabular}{|l|l|}
\hline$Q_{\text {Load }}$ & Reactive power demand \\
\hline$Q_{\text {com }}$ & Reactive power from compensator \\
\hline$Q_{I G}$ & Reactive power requirement of wind operated induction \\
\hline$Q_{S G}$ & Reactive power delivered by diesel operated \\
\hline$\Delta Q$ & Surplus reactive power in system during disturbances \\
\hline$\Delta Q_{S G}$ & Incremental change in synchronous generator reactive \\
\hline$\Delta Q_{F C}$ & Incremental change in fixed capacitor reactive power \\
\hline$\Delta Q_{S T}$ & Incremental change in STATCOM reactive power \\
\hline$\Delta Q_{I G}$ & Incremental change in induction generator reactive \\
\hline$\Delta Q_{L}$ & Incremental change in load reactive power \\
\hline$V$ & Load voltage \\
\hline$\Delta V$ & Incremental change in load voltage \\
\hline$\left(D_{v}\right)_{C L M}$ & Transfer function for composite load model \\
\hline
\end{tabular}

Revised Manuscript Received on February 05, 2020.

* Correspondence Author

Nitin Kumar Saxena*, Electrical \& Electronics Engineering Department, KIET Group of Institutions, Delhi-NCR, Ghaziabad, India. Email: nitinsaxena.iitd@gmail.com

Ashwani Kumar, Electrical Engineering Department, National Institute of Technology, Kurukshetra, India. Email: ashwa_ks@yahoo.co.in

Gebrehiwot Gebreyohans, Electrical and Computer Engineering Department, Wolaita Sodo University, Sodo, Ethiopia. Email: natanem2127@gmail.com

(C) The Authors. Published by Blue Eyes Intelligence Engineering and Sciences Publication (BEIESP). This is an open access article under the CC BY-NC-ND license (http://creativecommons.org/licenses/by-nc-nd/4.0/)

\begin{tabular}{|l|l|}
\hline$\left(D_{v}\right)_{S L M}$ & Transfer function for static load model \\
\hline$\left(D_{v}\right)_{D L M}$ & Transfer function for dynamic load model \\
\hline$\Delta P_{\text {wind }}$ & Input wind power incremental change \\
\hline$V_{d c}$ & DC voltage across the capacitor in STATCOM \\
\hline$k$ & STATCOM coefficient \\
\hline$B$ & STATCOM susceptance \\
\hline$\alpha$ & STATCOM firing angle \\
\hline$\Delta \alpha$ & STATCOM firing angle incremental change \\
\hline$K_{P}$ & Proportional constant of VAR generator \\
\hline$K_{I}$ & Integral constant of VAR generator \\
\hline$n$ & Load exponent coefficient \\
\hline$Q_{L}^{S}$ & Reactive power static load demand \\
\hline$Q_{L}^{I M}$ & Reactive power dynamic load demand \\
\hline$Q_{F C}^{S S}$ & Steady state value of Fixed capacitor reactive power \\
\hline$Q_{S T}^{S S}$ & Steady state value of STATCOM reactive power \\
\hline$Q_{S T}^{t s}$ & Transient state value of STATCOM reactive power \\
\hline$C_{F C}(x)$ & Fixed capacitor cost function \\
\hline$C_{S T}(x)$ & STATCOM cost function \\
\hline
\end{tabular}

\section{INTRODUCTION}

The isolated wind diesel electrical system has become more popular way of power generation due to high investment cost and transmission losses of grid connected power supply. Induction generators (IG) and synchronous generators (SG) have been used for getting power by wind source and fossil fuel (mostly diesel) respectively [1-2]. Available work has already been demonstrated the merits of such non grid connected hybrid system for power generation especially at remote areas [3-4]. A parallel research is going on to investigate the best choice of induction generator type for wind driven power generation. Permanent magnet induction generator (PMIG), permanent magnet synchronous generator (PMSG), self-excited induction generator (SEIG) and doubly fed induction generator (DFIG) have been suggested for interconnecting electric systems with wind turbine but SEIG is the most advantageous over others especially in isolated system. And therefore, SEIG is dominantly used generator in wind farms [5, 6]. Apart from several merits, requirement of self-excitation in SEIG has major concerns in its use. Reactive power is required for following operations; (i) steady state value of VAR load, (ii) induction generator voltage build up, (iii) reactive power for load and generator. If this VAR is not given to system, voltage starts to deviate from its steady state may go beyond the permissible range and it may not be desirable for consumers [7]. Hence, a sufficient amount of VAR should be supplied to the system operation for dynamic and steady state conditions. Such reactive power issues are governing as an important ancillary service for the system operations along with balancing the electric power supply and demand. 
In most of the available studies technical issues are discussed in which fast acting dynamic compensation is used to control the system voltage response in minimum time [8-11]. It has been investigated that the use of dynamic compensators alone makes the system compensation costly and static compensators alone cannot be used for voltage control.

Therefore, problem for selecting the best participation between static and dynamic compensators can be identified as an emerging economical issue.

Dynamic compensators adjust reactive power by adjusting their firing angle with the help of control mechanism in it. In ref. [12-15] conventional tuning method by minimizing performance index, genetic algorithm (GA), artificial neural network (ANN) and adaptive neuro fuzzy interface system (ANFIS) tuned fast dynamic compensators such as STATCOM (ST) and SVC have been proposed as reactive power compensating devices.

Load dynamics contributes much in system voltage performance and therefore must be considered in the technical and economical issues of system. However, the load dynamics have not been touched in most of available papers so far and only exponential type static load models are used in available studies. In [16] load interaction model is implemented for getting load response on reactive power compensation. Since the load characteristics depend on voltage inputs, the dynamic load with static load are therefore necessary for dynamics studies. Many papers have been published that mention loads composite load model. This model combines dynamic and static load together. Remote area based users can have the participation of static and dynamic load as 4 to 1 [17]. In ref. [18], ZIP-induction motor model, Exponential-induction motor model and Z-induction motor model are presented as three types composite load models.

Apart from load modelling, tuning of controllers' gain constant and hybrid participation of generation control, reactive power compensation is a thrust area form the point of view of technical and economical issues. In present scenario when $88 \%$ power generation through renewable energy sources are in the hand of private sectors [19] in India. Reactive power supply to control the system voltage must be remunerated accordingly and more importantly its tariff must be affordable for end users. The methodology for reducing STATCOM rating by introducing fixed capacitors for self-excitation of induction generator has been well documented in ref. [20]. In [21] four cases are presented for several participation schemes. Better voltage performance can be achieved with dynamic compensator alone but this method increases the compensation cost. In contrast of this compensation cost may become very low with static compensator but voltage response will be very poor in this condition. A hybrid approach in which static and dynamic devices are used together can reduce the overall compensation cost without compromising much with voltage response. And therefore, reactive power can be supplied using static and dynamic simultaneously and this arrangement presents a balance solution for the system voltage response and compensation cost.

Summarizing to all, this paper aims at contributing to; (i) development of composite load acquiring the combined properties of aggregate dynamic and static load, (ii) development of simulink model representing wind diesel base electrical system with composite load and reactive power balance equation during load and input changes, (iii) cost optimization of reactive power compensation using MATLAB program to find an acceptable compromise between costs and system voltage characteristics, and (iv) cost and performances comparison among proposed method (having optimum share of both the compensators, static and dynamic) and existing method (having compensator i.e. only STATCOM as dynamic part) for reactive power compensation.

\section{SYSTEM MODELING}

System is developed by connecting wind based induction generator, diesel based synchronous generator on same bus with composite load and reactive power compensators. 1.5 MW induction generator and 1.0 MW synchronous generator are modelled in this paper. Per unit values are used in simulink model with a common base of 2.5 MW power and $400 \mathrm{~V}$ voltage. In such system, synchronous generator, STATCOM and fixed capacitor generate reactive power while loads and induction generator demand reactive power from system. Let the system reactive power demand changes due to small changes in magnitude of $\Delta Q_{L}$ and $\Delta P_{\text {wind }}$. Instantaneous value of net change in system reactive power must be governed as;

$$
\Delta Q=\Delta Q_{S G}+\Delta Q_{F C}+\Delta Q_{S T}-\Delta Q_{I G}-\Delta Q_{L}
$$

Due to this change, steady state voltage deviates and it may become unstable if adequate and fast reactive power is not supplied to the system. Reactive power in system can be supplied by synchronous generator but at the cost of reduction in real power which is not acceptable. So, it is presumed that it generates only mandatory limit.

The system should have specialized reactive power compensators that must be operated with following features; (i) It must respond fast for dynamic changes in the system. This can be achieved by dynamic compensator,

(ii) The reactive power supply must be adequate to keep the system voltage in its acceptable range. This can be achieved by dynamic compensator, and

(iii) The cost of power compensation should not be imposed as the financial burden on the end user. The cost can be reduced enough if static device may have clubbed with dynamic device. Because, the cost through static compensator is cheaper than the cost through dynamic compensator.

To encapsulate all these features together, an optimization technique is required to decide the best participation between static and dynamic compensators. This optimization is presented in this paper with the help of interfacing between MATLAB simulink model and programming.

The algebraic equations for reactive power and components transfer functions for this isolated wind diesel based system are well explained and presented in [7-8, 11-12, 22-24]. An overall MATLAB simulink model is given in Fig. 1. Detail mathematics related with all system components is wee described in ref. [21]. 


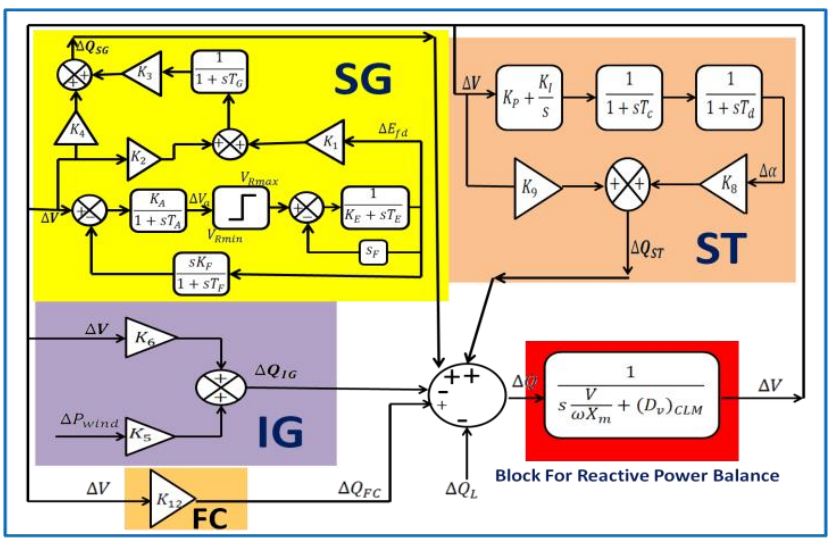

Fig. 1: Simulink block diagram for wind diesel system

Fig. 1 elaborates that dynamic condition occurs because of load change $\Delta Q_{L}$ or wind change $\Delta P_{\text {wind }}$. STATCOM and fixed capacitors are used as dynamic and static compensators respectively. Block of reactive power balance in Fig. 1 demonstrates how reactive power change will cause a change into electromagnetic absorption in load and induction generator dynamics and as a result, system voltage will change. To control this voltage, reactive power must be controlled rapidly by reactive power dynamic compensators. Therefore, STATCOM is the most important components to control the system voltage in dynamic conditions. The STATCOM details, in terms of block diagram, reactive power expression and transfer function model, are well explained in ref. [13]. Fig. 1 represents the block diagram of type-III small signal model, 12 pulse converter with unity modulation index STATCOM scheme having phase sequence delay, transport lag and PI regulator. Eq. 2 gives STATCOM power depending on two controlled variables firing angle $\alpha$ and voltage V. The STATCOM transfer function as in ref. [13] is,

$\Delta Q_{S T}(s)=k V_{d c} V B \operatorname{Sin} \alpha \Delta \alpha(s)-k V_{d c} B \operatorname{Cos} \alpha \Delta V(s)$

To decrease the cost of compensation, fixed capacitors banks are clubbed along with STATCOM. Fixed capacitor's expressions are well established in literature. Reactive power change with voltage variation for small perturbation is given in Eq. 3. Fig. 1 also represents to block diagram of fixed capacitor.

$$
\Delta Q_{F C}(s)=\frac{2 V}{X_{C}} \Delta V(s)
$$

STATCOM uses voltage as reference signal to adjust the firing angle and this is achieved by adjusting gain constants $\mathrm{KP}$ and KI. The accurate and precise value of KP and KI can make better compensation for the system in presence of advanced tuning methods like adaptive neuro fuzzy interface system (ANFIS), artificial neural network (ANN) and genetic algorithm (GA). All these methods provide comparable results but GA can be easily adopted for further studies to estimate the most suitable gain constant within the MATLAB coding. It should also be highlighted that the gain constants of STATCOM controller are tuned with the help of genetic algorithm as explained in ref. [13] in this paper.

\section{LOAD MODELING}

The studies in power system planning and operation focus on analysing the system behaviours with different load models. The system abnormal behaviours and instability can be suppressed with properly designed control schemes for known load patterns and therefore knowledge of existing load plays a key role for power system engineers in predicting the effects of disturbances and provides adequate control actions. High level safety cannot be achieved at the operator end, if the load modelling is not done properly [17]. Also it will derive the system towards an uneconomic system. However, mathematical modelling for exact load is complex due to several factors;

1. Existence of varieties of load

2. Load demand variation all the time

3. No much information about the loads characteristics

4. Random load change due to unpredictable disturbances

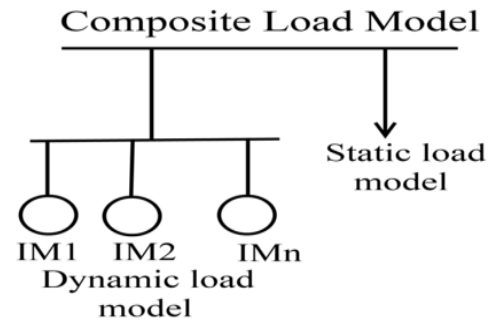

Fig. 2: Schematic for composite load

So, all the factors must be incorporate to model a load pattern in any power system study and this can be done if load designs by accompanying static load and aggregate dynamic load simultaneously. And therefore, composite load can be used to inherent the aggregate dynamic and static load models together in system [25]. Ref. [26] provides an outline to develop a composite load model. Fig. 2 gives a basic representation of composite load by including aggregate dynamic load model for shunt connected induction motor with static load in power system. Reactive power balance block in Fig. 1 demonstrates a term $D_{v}$ for load dynamics. This $D_{v}$ is the reactive power change with voltage for load. Most of the connected load at remote areas may be assumed residential and commercial type and for them ratio of dynamic load to static load may be preferred as 1:4 for simulation studies [27]. A 2.5 MW composite load is chosen. The total composite load is developed by inheriting the combined properties of aggregate dynamic and static load as shown in Table 1. Six induction motors (0.16 MW, 0.11 MW, 0.90 MW, 0.75 MW, 0.55 MW and 0.10 MW) are combined and a $0.5 \mathrm{MW}$ aggregate dynamic load is developed. The detail descriptions of different load models as shown in Table I are further explained in their corresponding subsections.

Table-I: Composite load developed by inheriting the combined properties of static and aggregate dynamic load

\begin{tabular}{|l|l|c|}
\hline \multicolumn{1}{|c|}{ Classification } & \multicolumn{1}{|c|}{ Model } & \multicolumn{1}{|c|}{$\begin{array}{c}\text { Total } \\
\text { capacity }\end{array}$} \\
\hline Static load & Exponential type model & $2.0 \mathrm{MW}$ \\
\hline Dynamic load & $\begin{array}{l}\text { Aggregate model of six induction } \\
\text { motors }\end{array}$ & $0.5 \mathrm{MW}$ \\
\hline Composite load & $\begin{array}{l}\text { Inherent the combined properties of } \\
\text { static and aggregate dynamic load }\end{array}$ & $2.5 \mathrm{MW}$ \\
\hline
\end{tabular}

\section{A. Modelling for exponential type model}

Static load is a load in which power is proportional to the instantaneous value of voltage and it is independent of the preceding voltage values.

\section{Published By:}


Reactive Power Cost Optimization Acquiring the Combined Properties of Static and Aggregate Dynamic Load as Composite Load Model

Constant current (I), constant impedance (Z), constant power (P), ZIP model and exponential model are the types of static load model [17, 26]. In ref. [12], expression for $\left(D_{v}\right)_{S L M}$ is developed and well documented as given in Eq. 4. $\left(D_{v}\right)_{S L M}=\frac{\Delta Q}{\Delta V}=n \frac{Q_{L}^{S}}{V}$

$\left(D_{v}\right)_{S L M}$ is estimated for $2.0 \mathrm{MW}$ static load by using value of load power factor and exponent coefficient equal to 0.9 lagging and 3 respectively as in ref [28].

\section{B. Modelling for $5^{\text {th }}$ order Induction motor model}

$D_{v}$ for fifth order induction motor of $0.5 \mathrm{MW}$ rating is evaluated in this section.

The induction motor specifications, provided by the manufacturer date as represented in Table 2, are used to find $D_{v}$ according to the following steps [29];

Equivalent circuit parameters for induction motor are obtained by using initial reference frame [30].

Using induction motor's differential equations as in ref. [26], their responses are plotted.

State space model is estimated as shown in Fig. 3 with variables of five differential equations as state vector, voltage as control vector and reactive power as disturbance vector. The expression for output response in terms of quadrature axes voltage and current are as following [31];

$Q_{L}^{I M}=V_{q s} I_{d s}-V_{d s} I_{q s}$

This state-space equation provides matrix of ABCD parameters of the order of $5 \times 5,5 \times 1,1 \times 5$ and $1 \times 1$ respectively [29].

These ABCD parameters can directly be used for estimating $D_{v}$.

The same procedure is also repeated for estimating the term $D_{v}$ for third order model. For 0.5 MW rating induction motor, step responses are seen for 5th and 3rd order model. Fig. 4 demonstrates the actual and zoom view of step response dynamics for its better understanding. It can be concluded that fifth order model is more dynamic compare to third order model and hence fifth order model is used for further studies in this paper.

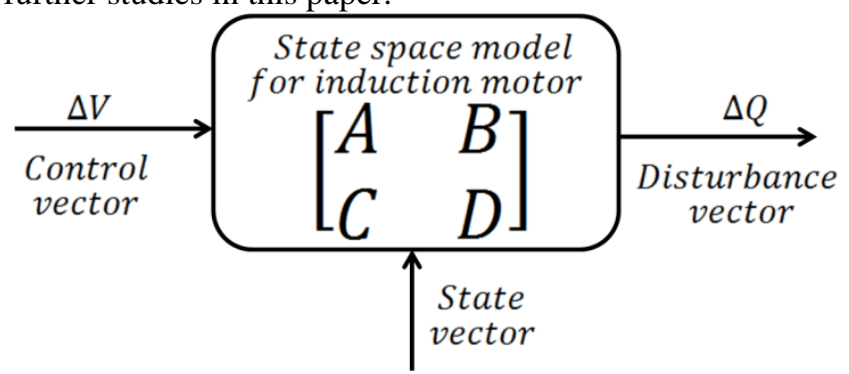

Fig. 3: State space induction motor model Step Response
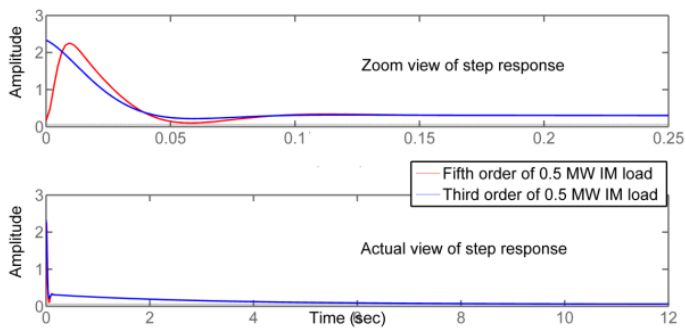

Fig. 4: Step responses for evaluated transfer function $\left(D_{v}=\frac{\Delta Q}{\Delta V}\right)$ of $0.5 \mathrm{MW}$ Induction motor

Table-II: Specifications for IM as dynamic load

\begin{tabular}{|c|c|c|c|c|c|c|c|}
\hline \multirow{2}{*}{$\begin{array}{l}\text { Motor } \\
\text { specifications for } \\
\text { full load }\end{array}$} & Single & \multicolumn{6}{|c|}{ IMs for aggregate model } \\
\hline & $\mathrm{IM}$ & (IM1) & (IM2) & (IM3) & (IM4) & (IM5) & (IM6) \\
\hline Induction motor & 0.50 & 0.16 & 0.11 & 0.90 & 0.75 & 0.55 & 0.10 \\
\hline Supply Voltage (in & & & & 400 & & & \\
\hline Frequency (in Hz) & & & & 50 & & & \\
\hline Power & & & & 0.9 & & & \\
\hline Efficiency & & & & 0.9 & & & \\
\hline Slip & & & & 0.04 & & & \\
\hline Pole pair & & & & 1 & & & \\
\hline
\end{tabular}

\section{Modelling for aggregate model of several induction motor}

The concept of aggregating all small induction motors into one induction motor is done in ref. [32]. Table 2 shows that a $0.5 \mathrm{MW}$ dynamic load is designed by clubbing six small induction motors of different ratings. In this study, it has been assumed that specifications of all the motor are equal and presented in Table II. The aggregate motor parameters are derived using energy conservation law [32-33]. Results of single unit of $0.5 \mathrm{MW}$ and aggregate model are estimated and compared as in Table III. Comparison in terms of their bode plots is also given in Fig. 5. Results verify the behaviour of aggregate model is almost similar to single unit induction motor load except the slight variation in dynamic parameters of motor. Therefore, an aggregate dynamic load model can be used to define a dynamic load model if the system has several induction motors.

Table-III: Estimated values for induction motors of 0.5 MW aggregate model

\begin{tabular}{|c|c|c|c|c|c|c|c|c|c|}
\hline & $\begin{array}{l}\text { Ratin } \\
\mathrm{g} \\
(\mathrm{kW})\end{array}$ & $\begin{array}{l}\mathrm{R}_{\mathrm{s}} \\
\text { (ohm } \\
\text { ) }\end{array}$ & $\begin{array}{l}\mathrm{R}_{\mathrm{r}} \\
\text { (ohm } \\
\text { ) }\end{array}$ & 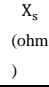 & 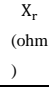 & $\begin{array}{l}X_{\mathrm{m}} \\
\text { (ohm } \\
\text { ) }\end{array}$ & $\begin{array}{l}\mathrm{J} \\
\left(\mathrm{kg} \cdot \mathrm{m}^{2}\right. \\
)^{2}\end{array}$ & $\mathrm{H}$ & $\begin{array}{l}\text { B } \\
\text { (N.m. } \\
\text { sec) }\end{array}$ \\
\hline IM1 & ${ }^{10}$ & 1.4377 & 0.4374 & 0.9920 & 0.8920 & 56.4913 & 0.007 & 0.0311 & 0.1163 \\
\hline IM2 & 55 & 0.2614 & 0.0795 & 0.1622 & 0.1622 & 10.2712 & 0.2 & 0.1615 & 0.6395 \\
\hline IM3 & 75 & 0.1917 & 0.0583 & 0.1189 & 0.1189 & 7.5322 & 0.3500 & 0.2073 & 0.8720 \\
\hline IM4 & 90 & 0.1597 & 0.0486 & 0.09991 & 0.0991 & 6.2768 & 0.40 & 0.1974 & 1.0465 \\
\hline IM5 & ${ }^{110}$ & 0.1307 & 0.0338 & 0.0811 & 0.0811 & 5.1356 & 0.61 & 0.2433 & 1.2790 \\
\hline IM6 & 160 & 0.0899 & 0.0273 & 0.0557 & 0.0557 & 3.5307 & 0.79 & 0.2193 & 1.86 \\
\hline Single unit of IM & 500 & 0.0288 & 0.0087 & 0.0178 & 0.0178 & 1.1 .1298 & 2.0 & 0.2576 & 5.8135 \\
\hline Aggregate Model & 500 & 0.0288 & $\begin{array}{ll}0.0087 \\
\end{array}$ & 0.0178 & 0.0178 & 1.1298 & 2.3571 & 0.2024 & 1.2684 \\
\hline
\end{tabular}

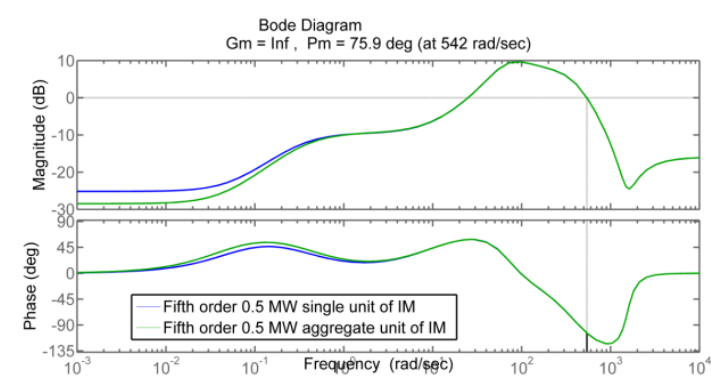

Fig. 5: Bode plots for 0.5 MW single unit and aggregate model of induction motor

\section{Composite load model: Modelling}

As in fig. 2, composite load acquires combined properties of static and aggregate dynamic load. $D_{v}$ for composite load is calculated as in Eq. 6 [26]. Fig. 6 represents the step response of composite load of $2.5 \mathrm{MW}$ along with static load of 2.0 MW and aggregate dynamic load of 0.5 MW.

Published By:

Retrieval Number: C6067029320/2020@BEIESP

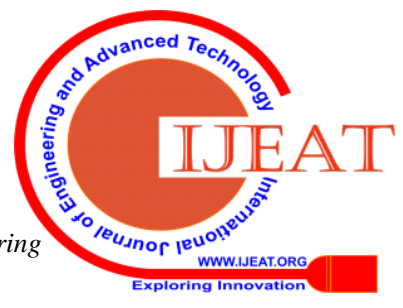


It can be concluded that though the dynamic load participation in total composite load is only $20 \%$ still the overall pattern follow the behaviour of dynamic load.

$\left(D_{v}\right)_{C L M}=\left(D_{v}\right)_{S L M}+\left(D_{v}\right)_{D L M}$

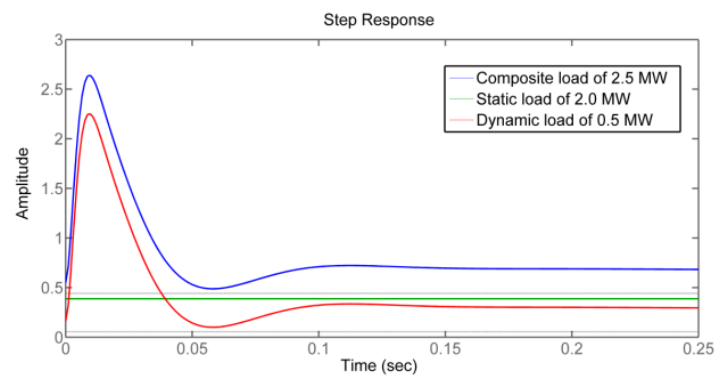

Fig. 6: Step responses for composite load of 2.5 MW

\section{REATIVE POWER COST OPTIMIZATION}

Under dynamic conditions, reactive power participation through compensators is decided on the basis of voltage waveform. This can be is examined with the help of transient parameters of voltage response such as maximum value of voltage rise and dip, settling time and rise time due to input wind and/or load disturbances. As discussed in previous section, the transfer function of all system components are combined together to design a complete MATLAB simulink model as shown in Fig. 1. International standard IEC 60038 permits $\pm 10 \%$ voltage variations in distribution system. So, a $10 \%$ step change is given to load reactive power and input real power for getting voltage disturbances at its extreme limit for compensation requirement studies. A sudden change in load reactive power disturbs voltage of the system. Connected compensating devices should respond fast to control this voltage along with fulfilment of steady state requirement. STATCOM has better performance for system voltage control but its operational cost is very high. FC alone cannot be used for system voltage control in spite of being cheaper compensating device. Cost of compensation can be decreased by adding static device with dynamic device but this method will compromise with voltage response. Selection of combined participation depends on system voltage and cost of compensation together [21]. Active power and reactive power both are lined with each other in power system still reactive power is one of the ancillary services that is priced separately for simplifying the system studies. Therefore, an optimization solution is found out using MATLAB for getting best proportion of both compensators together in this paper. Synchronous generator is not being considered for providing reactive power services beyond mandatory limit in this work. Mathematically, total reactive power supplied by dynamic and static compensators is;

$Q_{\text {com }}=Q_{I G}+Q_{\text {Load }}-Q_{S G}$

Since the system demands reactive power for two cases dynamic and steady state conditions. STATCOM alone has also been suggested in available papers to achieve better response but this arrangement offers high compensation cost. Therefore, instantaneous value for system compensation is given by Eq. 8 .

$Q_{\text {com }}=\left\{Q_{F C}^{S S}+Q_{S T}^{S S}\right\}+Q_{S T}^{t s}$

Instantaneous value for system compensation cost is given by Eq. 9.

$\left.C\left(Q_{\text {com }}\right)=\left\{C_{F C}\left(Q_{F C}^{S S}\right)+C_{S T}\left(Q_{S T}^{S S}\right)\right\}+C_{S T}\left(Q_{S T}^{t s}\right)\right\}$
These cost functions of fixed capacitor and STATCOM are evaluated by Eq. 10 and 11 respectively. Fixed capacitor's cost in \$ per hour is the multiplication of the purchased reactive power and depreciation rate [34]. In ref. [35], fixed capacitor cost function is presented and same is used in Eq. 10 ,

$C_{F C}=0.132 * Q_{F C}$ in $\$ / H r$

Similar to fixed capacitor cost function, STATCOM cost function is presented in ref. [36] and same is used in Eq. 11,

$C_{S T}=\frac{1000 * Q_{S T}}{8760 * 15}\left(0.0002466 Q_{S T}^{2}-0.2243 Q_{S T}+\right.$

150.527) in $\$ / H r$

Objective function;

Objective function $\mathrm{J}$ represents the total cost function of reactive power compensation as,

$J=C_{F C}\left(Q_{F C}^{S S}\right)+C_{S T}\left(Q_{S T}^{S S}\right)$

The problem is formulated by considering following two scenarios;

1. Reduction in compensation cost during steady state through STATCOM and fixed capacitor,

2. Participation of fixed capacitor with STATCOM keeping voltage in its pre-defined range.

Equality constraints for problem are,

$Q_{\text {demand }}=Q_{\text {release }}$

$Q_{\text {demand }}=Q_{I G}+Q_{L}-Q_{S T}$

$Q_{\text {release }}=Q_{F C}^{S S}+Q_{S T}^{s S}$

$0 \leq Q_{S T}^{S S} \leq Q_{\text {demand }}$

$0 \leq Q_{F C}^{S S} \leq Q_{\text {demand }}$

$V_{\min } \leq \Delta V \leq V_{\max }$

settling time $\leq$ settling time $e_{\text {acceptable }}$ (18)

Mathematical formulation of problem is arranged in MATLAB $\mathrm{m}$ file for getting the results. Interfacing of simulink model is done with it for estimating the required parameters through simulink model. The algorithm which is used for this optimization technique is as following;

- Estimate the steady state reactive power requirement using Eq. 7.

- Supply this total reactive power through STATCOM only and develop voltage response of the system. This is marked as reference case and denoted as case I.

- Evaluate voltage sag and swell and settling time for case I.

- Using parameters of case I, define the parameters for case II.

- Choose numbers of sample satisfying the total reactive power as estimated by Eq. 7 and define incremental change in the value of fixed capacitor and STATCOM in every sample.

- For every sample, estimate the parameters from voltage as given above.

- Compare the transient parameters for each sample with case I.

- Sort those samples only that satisfying the defined acceptable range of parameters.

- Using Eq. 9, estimate the reactive power compensation cost for every sorted sample.

- Select the sample as optimized case II having the minimum value of compensation cost. 


\section{RESULTS AND DISCUSSIONS}

Reactive power market design is not so easy due to its local generation at consumers' end. Reactive power can directly be provided by the producers to control the voltage in the system. Moreover, cost can be decided by the producers depending upon the reactive power compensation schemes. It should also be noticed that continuous power supply is more important than its quality at some far located areas.

Though the involvement of static device with dynamic device decline the voltage response in the system but also it decreases the system overall compensation cost and hence optimization procedure is suggested for implementing exact reactive power compensation scheme especially with composite load.

Optimization procedure is explained with suitable algorithm in previous section. In previous section, compensation cost is also investigated with $2.5 \mathrm{MW}$ system. To investigate the role of dynamic load on compensation cost analysis, results for static load of $2.5 \mathrm{MW}$ are compared with composite load as described in Table 1. Costs, for case I in which compensation is provided with STATCOM only and for case II in which compensation is provided by the optimize values of dynamic and static compensators, are also compared for two load patterns. The procedure for developing load transfer function for reactive power change with voltage change has been discussed in last section. Optimization is done with 10000 samples of reactive power participation between STATCOM and fixed capacitor. The acceptable range of transient parameters for sorting the samples is considered as following;

- Voltage stability

- Voltage rise and dip should not be exceeding more than 0.05 pu of reference case values.

- Settling time should not be more than $0.01 \mathrm{sec}$ of reference case.

Steady state reactive power requirements are shown in Table IV. Negative convention is being used for reactive power absorbing and positive convention is being used for reactive power generating unit in this system. It can be analysed that induction and synchronous generators reactive power requirement is same in both the cases but as the total load reactive power demand is increasing with composite load and therefore compensator has to release more reactive power for controlling the system voltage. If only STATCOM is used, the compensation cost will increase more and hence this compensation cost is tried to reduce by optimization method in this paper. A comparative analysis for compensation cost for two load patterns as in Table IV is presented in Table V. Fig. 7 and 8 gives the voltage and STATCOM response for both the load patterns in reference and optimized case. Results show how the reactive power compensation cost reduce by the participation of fixed capacitor with STATCOM on compromising the system voltage response up to some extent. Since most of the realistic load is of composite load type and Fig. 7 and 8 represents that voltage response is less affected in composite load pattern. This approves the optimize selection of STATCOM and fixed capacitor for controlling the system voltage to reduce the system compensation cost.

Table-IV: Per unit steady state reactive power requirement in system

\begin{tabular}{|c|c|c|c|l|l|l|}
\hline Load type & $\mathrm{Q}_{\mathrm{SG}}$ & $\mathrm{Q}_{\mathrm{IG}}$ & $\mathrm{Q}_{\mathrm{SLM}}$ & $\mathrm{Q}_{\text {DLM }}$ & $\mathrm{Q}_{\text {CLM }}$ & $\mathrm{Q}_{\text {com }}$ \\
\hline Load & 0.082 & -0.153 & -0.161 & 0 & 0 & 0.232 \\
\hline Load & 0.082 & -0.153 & -0.129 & -0.053 & -0.182 & 0.253 \\
\hline
\end{tabular}

in $2.5 \mathrm{MW}$ test system

\begin{tabular}{|l|l|l|r|r|}
\hline & \multicolumn{2}{|c|}{ Load pattern 1 (Static } & \multicolumn{1}{c|}{ Load pattern 2 (Composite } \\
\hline Response & Case I & Case II & \multicolumn{1}{c|}{ Case I } & \multicolumn{1}{c|}{ Case II } \\
\hline$Q_{F C}^{S S}(\mathrm{pu})$ & 0 & 0.1236 & 0 & 0.1492 \\
\hline$Q_{S T}^{S S}(\mathrm{pu})$ & 0.2325 & 0.1089 & 0.2535 & 0.1043 \\
\hline$Q_{S T}^{t s}(\mathrm{pu})$ & 0.2041 & 0.2041 & 0.2067 & 0.2067 \\
\hline$Q_{\text {total }}(\mathrm{pu})$ & 0.4366 & 0.4366 & 0.4602 & 0.4602 \\
\hline$C_{F C}\left(Q_{F C}^{S S}\right)(\$ \mathrm{per}$ & 0 & 0.0408 & 0 & 0.0492 \\
\hline$C_{S T}\left(Q_{S T}^{S S}\right)(\$$ per & 0.6656 & 0.3118 & 0.7257 & 0.2987 \\
\hline$C_{S T}\left(Q_{S T}^{t s}\right)(\$$ per & 0.5843 & 0.5843 & 0.5918 & 0.5918 \\
\hline$C\left(Q_{\text {total }}\right)(\$$ per & 1.250 & 0.9370 & 1.3175 & 0.9397 \\
\hline
\end{tabular}

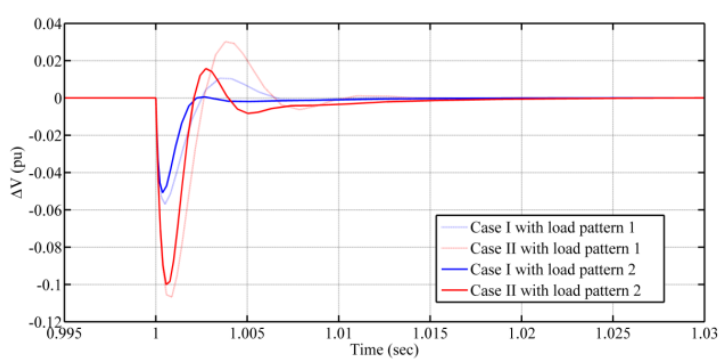

Fig. 7: Comparison of voltage responses for load pattern 2 in $2.5 \mathrm{MW}$ test system

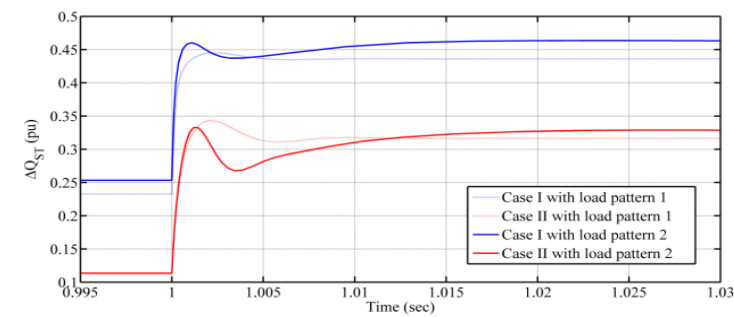

Fig. 8: Comparison of STATCOM response for load pattern 2 in 2.5 MW test system

\section{CONCLUSIONS}

Composite load acquiring the combined properties of static and aggregate dynamic load is developed in this paper. Compensation cost is estimated for proposed system. Induction motor is taken as dynamic load and it is demonstrated how the $5^{\text {th }}$ order induction motor is more realistic compare to third order model. Due to which the fifth order model is considered for this study. Method to explore aggregate dynamic load is demonstrated. Results are also analyzed and compared for single unit and aggregate unit with their bode plots. Step responses of developed composite load with static and aggregate dynamic load are also demonstrated to explain their corresponding behaviour. It has been concluded that dynamic compensation play main role in dynamic conditions but reactive power requirement for two distinguished conditions steady state condition and dynamic condition gives opportunity to reactive power providers to optimize the participation between dynamic and static compensators. The optimize selection of both compensators together makes system cheaper with specified tolerance in system characteristics. Table 3 and 4 demonstrate how system compensation cost reduces with compromising system voltage response. Voltage rise, voltage dip and settling time are the system parameters which are used to specify the tolerance range of voltage response.

\& Sciences Publication 
Recapitulating to the all facts and figures, the outcome of this study gives a procedure to choose cost based optimum static and dynamic compensations for the isolated hybrid wind diesel based electrical system in presence of composite load.

\section{REFERENCES}

1. Hunter R, Elliot G., "Wind-diesel systems, a guide to the technology and its implementation" Cambridge: University Press, 2005.

2. R.K. Viral, D.K. Khatod,m "Optimal planning of distributed generation systems in distribution system: A review" Renewable and Sustainable Energy Reviews, vol. 17, no. 7, pp. 5146-5165, 2012.

3. Farhad Shahnia, Majumder Ritwik, Ghosh Arindam, Ledwich Gerard, Zare Firuz, "Operation and control of a hybrid microgrid containing unbalanced and nonlinear loads" Electric Power Systems Research, vol. 80, pp. 954-965, 2010.

4. Lopes J A, Hatziargyriou N, Mutale J P, Jenkins N., "Integrating distributed generation into electric power system: A review of drivers, challenges and opportunities" Electric Power System Research, vol 77, no. 9, pp. 1189-1203, 2007.

5. Sulkowski W, Sharma P, Hoff B., "Optimal controllers designs for automatic reactive power control in an isolated wind-diesel hybrid power system" Electrical Power and Energy Systems, vol. 81, pp. 387-404, 2016.

6. Sandhu K. S., Jain S. P., "Steady state operation of self-excited induction generator with varying wind speeds" International Journal of Circuits, Systems And Signal Processing, vol. 2, no. 1, 2008.

7. Kassem,A. M., Abdelaziz, A.Y., "Firefly Optimization Algorithm for the Reactive Power Control of an Isolated Wind-Diesel System" Electric Power Components and Systems, vol. 45, no. 13, pp. 1413-1425, 2017.

8. Bansal R. C.. "Automatic reactive-power control of isolated wind-diesel hybrid power systems" IEEE Transactions on Industrial Electronics, vol. 53, no. 4, 2006.

9. Ashish Sharma, Gagandeep Kaur., "Assessment of Capacitance for Self-Excited Induction Generator in Sustaining Constant Air-Gap Voltage under Variable Speed and Load" Energies, vol. 11, no. 10, pp. 1-16 2018.

10. Sharma P, Bhatti T S., "Performance investigation of isolated wind-diesel hybrid power systems with WECS having PMIG" IEEE Trans Industrial Electronics, vol. 60, no. 4, pp. 1630-37, 2013.

11. Saxena N. K., Kumar A., "Dynamic Reactive Power Compensation and Cost Analysis for Isolated Hybrid Power System" Electric Power Components and Systems, vol. 45, no. 18, pp. 2034-2049, 2018.

12. Saxena Nitin Kumar, Kumar Ashwani, "Reactive power compensation of an isolated hybrid power system with load interaction using ANFIS tuned STATCOM" Frontiers in Energy, vol. 8, no. 2, pp. 261-268, 2014.

13. Saxena Nitin Kumar, Kumar Ashwani, "Reactive Power Control in Decentralized Hybrid Power System with STATCOM Using GA, ANN and ANFIS Methods" International Journal of Electrical Power and Energy Systems, vol. 83, pp. 175-187, 2016.

14. Saxena Nitin Kumar, Kumar Ashwani, "Voltage control using self-trained ANFIS with probabilistic wind input and load pattern", In Annual IEEE India Conference INDICON-2015, Jamia Milia Islamia, New Delhi, 2015.

15. Sharma P, Saxena Nitin Kumar, Bhatti T. S., "Study of Autonomous Hybrid Power System using SVC and STATCOM" In International conference of power system ICPS-2009, IIT Kharagpur, India, 2009.

16. Saxena Nitin Kumar, Kumar Ashwani, "Load Modelling Interaction on Hybrid Power System using STATCOM" In INDICON-2010, Jadavpur University, Kolkata, India, 2010.

17. Parveen Tania, "Composite load model decomposition: induction motor contribution" PhD Thesis, Faculty of Built Environment and Engineering, School of Engineering Systems, Queensland University of Technology, 2009

18. Kim Byoung Ho, Kim Hongrae, Lee Byoungjun, "Parameter Estimation for the Composite Load Model" Journal of International Council on Electrical Engineering, vol. 2, no. 2, pp. 215-218, 2012.

19. A report by Government of India, Ministry of Power, Central Electricity Authority, "Executive Summary: Power Sector" New Delhi, India, 2015.

20. Singh Bhim, Murthy S S, Gupta Sushma, "Analysis and design of STATCOM based voltage regulator for self-excited induction generators" IEEE Transactions on Energy Conversion, vol. 19, no. 4, pp. 783-790, 2004

21. Saxena Nitin Kumar, Kumar Ashwani, "Analytical comparison of static and dynamic reactive power compensation in isolated wind diesel system using dynamic load interaction model" Electric Power Components and Systems, vol. 53, no. 5, pp. 508-519, 2015.

22. Bansal R C, Bhatti T S, Kothari D P, "A novel mathematical modelling of induction generator for reactive power control of isolated hybrid power systems" International Journal of Modelling and Simulation, vol. 24, no. 1, pp. 1-7, 2004.

23. Sharma Pawan, Bhatti T S, Ramakrishna K S S, "Control of reactive power of autonomous wind-diesel hybrid power systems" In joint international conference on Power Electronics, Drives and Energy Systems PEDES \& 2010 Power India, 2010.

24. Kassem Ahmed M, Yousef Ali M, "Robust control of an isolated hybrid wind-diesel power system using Linear Quadratic Gaussian approach" Electrical Power Energy System, vol. 33, pp. 1092-100, 2011.

25. Yinhong Li, Hsiao-Dong Chiang, Byoung-Kon Choi, Yung-Tien Chen, Der-Hua Huang, Mark G. Lauby, "Load models for modeling dynamic behaviors of reactive loads: Evaluation and comparison" Electrical Power and Energy Systems, vol. 30, pp. 497-503, 2008.

26. Kundur P, "Power System Stability and Control" Tata-Mcgraw-Hill, India, 2006.

27. Fahmy O M, Attia A S, Badr M A L, "A Novel Analytical Model for Electrical Loads Comprising Static and Dynamic Components" Electric Power Systems Research, vol. 77, pp. 1249-1256, 2007.

28. Seo Eun Son, Soo Hyoung Lee, Dong-Hee Choi,Yung Bin Song, Jung Do Park et al., "Improvement of Composite Load Modeling Based on Parameter Sensitivity and Dependency Analyses" IEEE Transactions on Power System, vol. 29, no. 1, pp. 242-250, 2014.

29. Saxena Nitin Kumar, Kumar Ashwani, "Estimation of Composite Load Model with Aggregate Induction Motor Dynamic Load for An Isolated Hybrid Power System" Frontiers in Energy, vol. 9, no. 4, pp. 472-485, 2015.

30. Nitin Kumar Saxena, Ashwani Kumar, "Analytical approach to estimate mechanical parameters in induction machine using transient response parameters" International Transaction on Electrical Energy System, vol. 29, no. 3, 2019.

31. Krause P C, "Analysis of Electric Machinery" McGraw-Hill Book Company, 1986

32. Aree Pichai, "Aggregating Method of Induction Motor Group Using Energy Conservation Law" ECTI Transactions on Electrical Engineering, Electronics and Communications, vol. 12, no. 1, 2014.

33. Pedra Joaquin, Sainz Luis, Corcoles Felipe. "Study of Aggregate Models for Squirrel-Cage Induction Motors" IEEE Transactions on Power Systems, vol. 20, no. 3, pp. 1519-1527, 2005.

34. Rogers A L, Manwell J F, McGowan J G, Ellis A F, "Design requirements for medium-sized wind turbines for remote and hybrid power systems" Renewable Energy, vol. 26, pp. 157-168, 2002.

35. Murty V V S N, Kumar Ashwani, "Comparison of optimal capacitor placement methods in radial distribution system with load growth and ZIP load model" Frontiers in Energy, vol. 7, pp. 197-213, 2013.

36. Wenjuan Zhang, "Optimal sizing and location of static and dynamic reactive power compensation" Ph.D. Thesis, The University of Tennessee, Knoxville, 2007

\section{AUTHORS PROFILE}

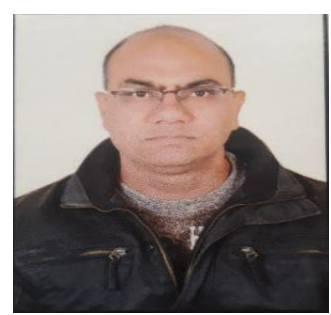

Nitin Kumar Saxena, an academician cum career counselor of having more than 16 years' experience in engineering teaching and research fields, has received his Ph.D., M.Tech. and B.E. from National Institute of Technology Kurukshetra, Indian Institute of Technology Delhi and MJP Rohilkhand University Bareilly respectively. Presently, he is working as Associate Professor in KIET, Ghaziabad, India. Before this, he has worked as Associate Professor in Wolaita Sodo University, Ethiopia and Assistant Professor in MIT, Moradabad, India. He has published number of research papers in several reputed international and national journals and conferences along with several books and chapters. His broad area of interest includes power systems, FACTS, and hybrid power systems, and he is a life member of the Indian society of Technical education. 


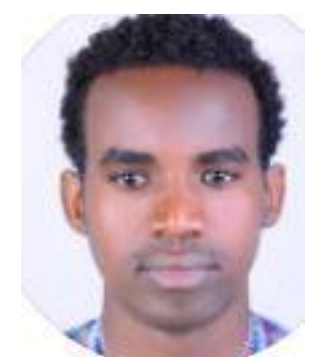

Ashwani Kumar received his Ph.D. from the Department of Electrical Engineering, IIT Kanpur, India in 2003 and his B.Tech. in 1988 and M.Tech. in 1994 from G. B. Pant University, Pant Nagar and PEC Chandigarh, respectively. He did advance research work from Tennessee Technological University, USA for his postdoctoral fellowship from Jan 2008 to May 2008. He is currently working as a professor in Electrical Engineering Department, NIT Kurukshetra, India. He has published a number of research papers in refereed international/national journals and in proceedings of international/ national conferences. His fields of interest are power systems, power systems restructuring, distributed generation and renewable energy systems, facts applications to power systems, demand side management, electricity price forecasting, power system dynamics.

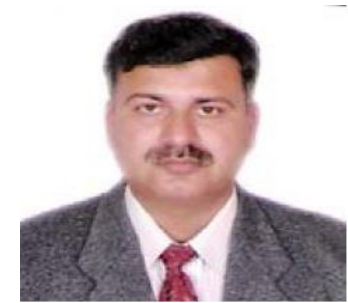

Gebrehiwot Gebreyohans received his B.Sc. in Engineering from Mekelle Univertity, Ethiopia and M.Sc. in Engineering from Jimma Univresity in 2019. Presently, he is working as faculty member in Wolaita Sodo Un iv ersity, Sodo, Ethiopia. His research area of interest is load forecasting in power system. 